Michał Bijak, Ewelina Synowiec, Jacek Grębowski Joanna Kołodziejczyk-Czepas and Michał Ponczek

\title{
6. METHODS OF DETECTING BIOLOGICAL MATERIALS
}

The rapid detection of Biological agents is one of the most important steps in the process for first responders to bioterrorist attacks. Confirmation of a bio-agent's presence and where it most likely occurred, as well as precise identification of the agent, are key elements of action in addressing the effects of human exposure using appropriate medical procedures, and limiting the agent's spread. Biological weapons can be deployed in two ways: as hidden attacks, or as part of public displays of terrorism. In the case of a hidden attack, a diagnosis of the use of biological agents will always be delayed because the first suspicions will occur only after analysis of the epidemiological data, and when it indicates that non-endemic variables are present. In this case, analysis of the agent used will be based on typical microbiological methods (bacterial culturing), and advanced molecular biology techniques (genotyping of the pathogen). Detection and characterisation in this case will be carried out at specialised biological laboratories. However, in the second type of attack, involving the explicit use of a biological agent, initial detection of the material used should be one of the most important elements in any organised response system. A quick analysis allows for possible acknowledgment of the threat, and thus exclusion of false alarms. Information about the initial determination of whether a dangerous agent has been used and spread, as well as other potential factors in the attack, provides the basis for the on-site incident manager to take further action - evacuation, isolation, and medically preventive actions (such as rapid implementation of antibiotic treatment). It should be noted, then, that only true, accurate knowledge of the exact characteristics of the biological agent used allows for proper preventive and therapeutic action.

The methods used for detecting biological pathogens should consist of the following criteria:

- Quantitative abilities;

- Multiplexing capabilities;

- High specificity;

- High sensitivity.

Traditional detection methods, such as microscopic identification of characteristic morphological differences in bacterial, enzymatic and staining 
test methods can be less specific than needed, and can be time-consuming and inefficient. Analysis should include a cascade of actions using increasingly more sophisticated research methods that narrow down the exact agents involved. As such, the system described in the following pages has been developed as a result of the analysis of various existing methodologies. Proposition of this scheme is presented below:

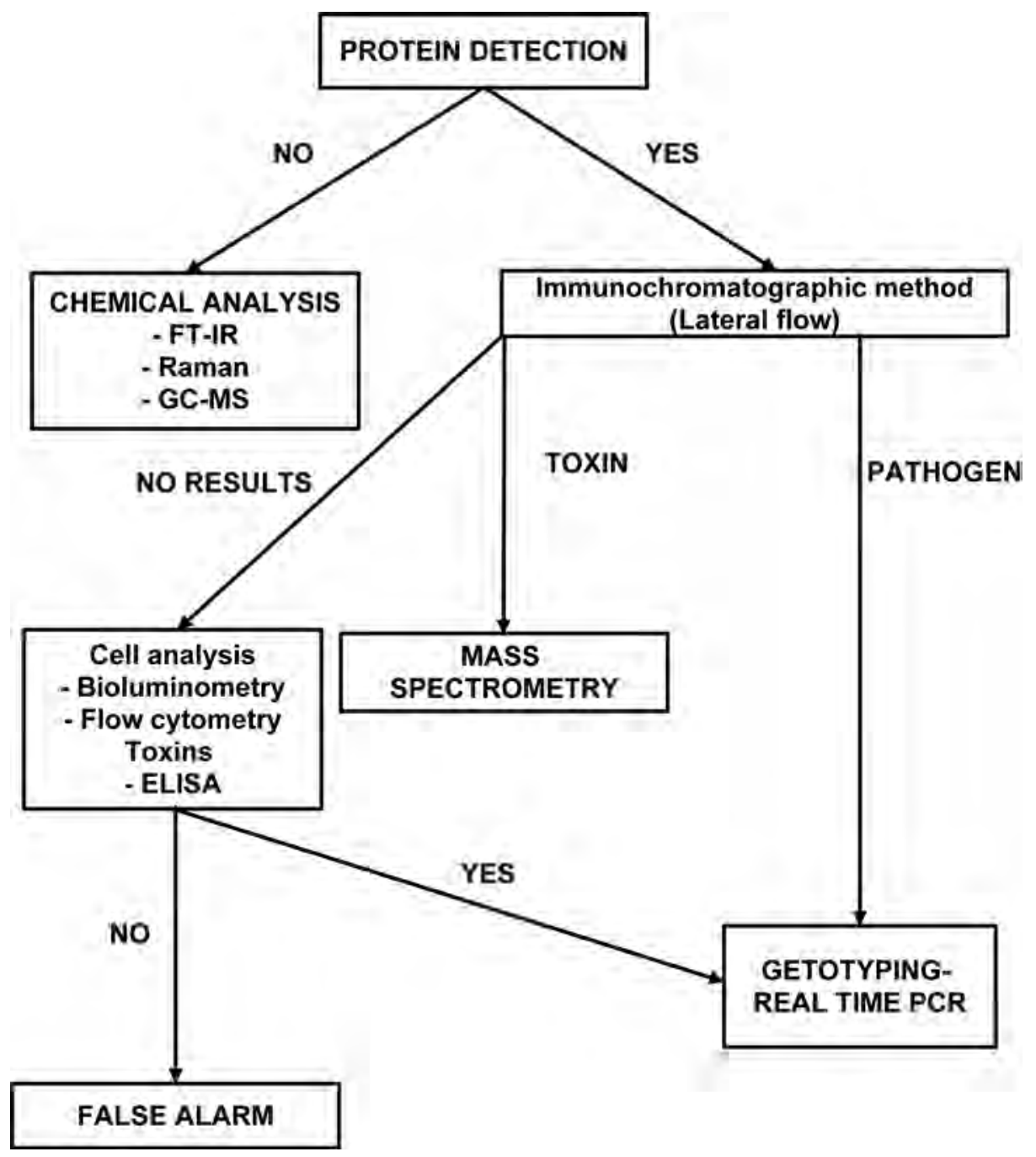

Figure 1. Proposition of cascade biodetection scheme 


\subsection{Proteins}

Proteins are the basic building element of each living cell, as well as the main component of the outer shell of viruses, which according to the current concept of biology, is not considered part of a living organism. In addition, protein structure also contains a great amount of biological toxins (although there are some exceptions, for example T-2 mycotoxins). Thus, the confirmation or exclusion of the presence of protein in a sample will allow for an initial assessment of the presence of a hazardous biological agent. For this reason, determination of the presence of protein should be the first step in analysing biological materials recovered from the action scene. Such analysis should be very simple to implement and the time needed to complete it short. In addition, a very important element of the selected diagnostic method should be its sensitivity (i.e. the detection threshold), because the amount of bio-agent in the sample may be relatively small compared to the filler material, which is very often a non-protein substance/substances.

Proteins are large biomolecules, or macromolecules, consisting of one or more long chains of amino acid residue. All amino acids possess common structural features, including an $\alpha$-carbon to which an amino group, a carboxyl group, and a variable side chain are bonded. Only proline differs from this basic structure as it contains an unusual ring to the $\mathrm{N}$-end amine group, which forces the $\mathrm{CO}-\mathrm{NH}$ amide moiety into a fixed conformation. A linear chain of amino acid residues is called a polypeptide. The amino acids in a polypeptide chain are linked by peptide bonds. The peptide bond is formed when the carboxyl group $(\mathrm{COOH})$ of one amino acid molecule reacts with the amino group $\left(\mathrm{NH}_{2}\right)$ of the other amino acid molecule, causing the release of a molecule of water $\left(\mathrm{H}_{2} \mathrm{O}\right)$. Hence the process is a dehydration synthesis reaction (also known as a condensation reaction). Proteins in their structure can contain the residue of from a few dozen to several thousand amino acids.

In biochemical analysis, many methods of determining the protein content of a sample have been used over the years. The most popular of these are based on the UV absorbance method, as well as on colorimetric methods such as the Biuret method, the Lowry Protein Assay, the Bradford method, and the bis-cinchonine acid method (BCA).

Spectrophotometric methods (including colorimetric analyses) of protein concentration in different samples are based on measurements of sample absorbance at different light wavelengths. Measurements can be made using different types of cuvettes or microtiter plates. Most popular cuvettes have a volume of $1.5-3 \mathrm{ml}$ and are made of plastic, optic glass or quartz glass. The choice of cuvette type should be appropriate to the volume of the material being examined, and in particular to the spectroscopic method used (e.g. ultraviolet/UV 
assay, colorimetric assay or fluorimetric methods). When the use of spectroscopic equipment is not an option, a simple colorimetric assay can be made by eye.

Spectrophotometric analysis under ultraviolet (UV) light is one of the simplest methods of protein detection, or quantification. Polypeptide chains contain amino acids with a characteristic cyclic (aromatic) structure. For example, tyrosine, phenylalanine and tryptophan, which are able to absorb UV radiation at $280 \mathrm{~nm}$. The presence of these amino acids may be a basis for protein detection or simple quantification of protein content by $\mathrm{A}_{280}$ measurement. Other methods for protein quantification include measurements made at $205 \mathrm{~nm}$, corresponding to the UV absorption of peptide bonds. However, there are numerous chemical and practical aspects that limit the possibility of quantitative evaluation of protein concentration using these methods. The most significant of these is that an extinction coefficient of the examined protein must be established. Measurements in the UV range (wavelengths up to $400 \mathrm{~nm}$ ) need to be made using quartz glass or plastics, without UV absorption, especially made for use in this spectrum.

The vast majority of current biochemical methods of protein quantification are based on various types of colorimetric assays. Colorimetry is an analytical technique that is widely used to determine the concentration of substances based on the intensity of their colour (measured at appropriate wavelengths). Chemical structures of many compounds, including proteins and other biomolecules, contain some structural fragments that are able to absorb visible spectrum (VIS) radiation, and these are called 'chromophores'. The visible spectrum covers wavelengths of between 400 and $800 \mathrm{~nm}$, which may be detected using quartz glass, optic glass and plastic laboratory equipment. The absorptive capability of VIS radiation at different wavelengths by various substances results in the substances taking on distinctive colours. For instance, compounds able to absorb radiation at wavelengths of $400-420 \mathrm{~nm}$ turn yellow, while substances strongly absorbing radiation of about $600-750 \mathrm{~nm}$ are mainly purples, or intense blues. Thus, a chromophore may be defined as the part of a molecule responsible for its colour. The $\mathrm{C}=\mathrm{C}$ - and $\mathrm{N}=\mathrm{N}$ bonds, $\mathrm{C}=\mathrm{O}$ and $\mathrm{N}=\mathrm{O}$ groups as well as aromatic rings all belong to the most common chromophores. However, only part of the molecules (inc. proteins such as haemoglobin) possesses a natural colour that can be assayed directly. Therefore, the concentration of most substances can be determined indirectly, using chemicals that react with the examined compound (or a product of its chemical activity), in order to generate a coloured substance.

A panel of colorimetric assays commonly applied in protein quantitation includes different protocols based on the Lowry assay, Bradford assay, Pierce 660 assay and BCA assay. Mostly, colorimetric assays are based on the detection of coloured products/complexes resulting from reactions between cuprous ions $\left(\mathrm{Cu}^{+}\right)$and proteins and/or reagents. These methods are classified as copperbased assays. The reagent mixtures contain cupric ions $\left(\mathrm{Cu}^{2+}\right)$, which undergo 
a reduction to $\mathrm{Cu}^{+}$under alkaline conditions. The $\mathrm{Cu}^{+}$ions are able to react with peptide bonds (the 'biuret reaction'), the aromatic ring of tyrosine, the indole part of tryptophan, the thiol groups of cysteine residue in proteins, and with chemical reagents, leading to the formation of detectable products. In most proteins the content of tryptophan or cysteine is significantly lower than the amount of tyrosine residue, and so these assays are primarily dependent on the presence of tyrosine.

The Lowry assay is one of the most popular methods for determining the total protein content of a biological sample, including biological material, originated from human, animal and bacterial sources. The combination of the Biuret method and two types of reaction provides a very sensitive reaction, for example oxidation of peptide bonds generating $\mathrm{Cu}^{+}$ions (1), and the reaction of the ions with FolinCiocalteau reagent (sodium 1,2-naphthoquinone-4-sulfonate) (2). This allows for detection of proteins even at concentrations of $10 \mu \mathrm{g} / \mathrm{ml}$ (the sensitivity range is $10-1000 \mu \mathrm{g} / \mathrm{ml})$. The formation of an intensively blue product can be recorded at $750 \mathrm{~nm}$.

Another popular method, based on a combination of the biuret reaction and complexation of the generated $\mathrm{Cu}^{+}$ions, is the bicinchoninic acid (BCA) assay. This method is based on a combination of two chemical reactions. The first is the biuret reaction, in which amino acids in the protein structure reduce the cupric ions $\left(\mathrm{Cu}^{2+}\right)$ to cuprous ions $\left(\mathrm{Cu}^{+}\right)$in an alkaline solution. The second step is colorimetric detection of the product of cuprous ions and BCA complexation/ chelation. The chelation of one cuprous ion by two molecules of BCA yields a purple-coloured product, with a maximum absorption of $562 \mathrm{~nm}$. Since the formation of these complexes has a linear and dose-dependent character, and is reproducible in a relatively broad range (approx. 20-2000 $\mu \mathrm{g} / \mathrm{ml}$ ), the BCA assay is considered to be very useful for testing different samples containing proteins. It is easy to execute and requires only small amounts of protein samples $(20-25 \mu \mathrm{l})$. The procedure can also be modified according to the type or concentration of the protein-containing samples. However, there are some very important limitations and disadvantages, chief of which is that the reactions develop over time. Additionally, certain substances (such as detergents, reducing agents, biogenic amines or chelating compounds), are known to interfere with this method. But modified BCA reagents that can be used in the environment of detergents and reducing agents are available on the commercial market.

The next most popular method of fast protein analysis is the Bradford assay, which represents a different type of analytical method. The chemical basis of this reaction is the direct reaction of Coomassie Brilliant Blue G-250 dye with amino acids in the protein structure. This reaction is primarily mediated by reactions with arginine, lysine and histidine. During the assay, a brown/red coloured dye reacts with proteins under acidic conditions, yielding complexes with a blue colour that can be detected by eye. The sensitivity of this method is dependent on 
the molecular weight of the assayed proteins and is proportional to the number of positive charges in the proteins. The assay is compatible with most buffers, as well as reducing and chelating compounds. The main limitations and disadvantages of the Bradford assay is that it is not suitable for polypeptides of low molecular mass - the molecular weight of the assayed proteins must attain at least 3,000 Daltons, but most bio-threats will have proteins with a higher mass.

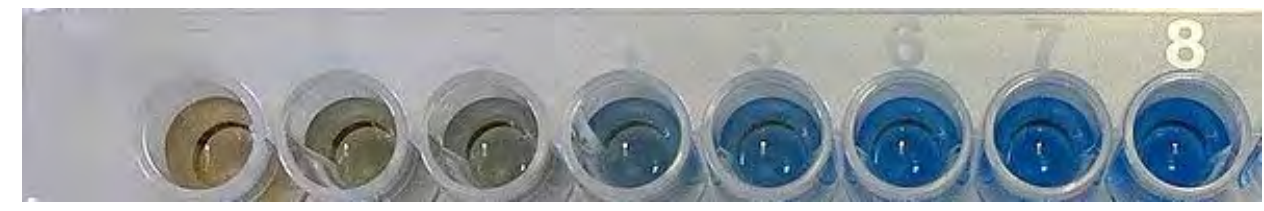

Figure 2. Changes of Bradford dye in different protein concentrations

The Pierce ${ }^{\mathrm{Tx}} 660 \mathrm{~nm}$ Protein Assay is a very interesting, commercially available reagent kit. It is based on the use of a dye-metal complex (polyhydroxybe nzenesulfonephthalein-type dye and a transition metal), which as in the Bradford reacts with amino acid residue. The dye-metal complex begins as a reddishbrown colour and changes to green upon protein binding. The colour change is produced by deprotonation of the dye at low $\mathrm{pH}$, facilitated by interactions with positively charged amino acid groups in proteins. Therefore, the dye mainly interacts with basic residues in proteins, such as histidine, arginine and lysine, and to a lesser extent tyrosine, tryptophan and phenylalanine. The colour produced in the assay is stable and increases in proportion to a broad range of increasing protein concentrations. In comparison to the Bradford, this assay is more linear and compatible with higher concentrations of most detergents, reducing agents and other commonly used reagents. The Pierce $660 \mathrm{~nm}$ is recommended as a quick method of quantifying proteins in a range of $25-2000 \mu \mathrm{g} / \mathrm{ml}$. Although the Pierce $660 \mathrm{~nm}$ Protein Assay produces a higher level of protein-to-protein variation (37\%) than other assays, such as the BCA Protein Assay, the simpler single-reagent format and broader substance compatibility make the Pierce $660 \mathrm{~nm}$ Assay more convenient for many routine applications.

However all of protein detection methods have one big limitation. To proper detection of proteins to smart detection kit must be added some bacterial cell lysing agent such as DNAzol or Lyse it ${ }^{\circledR}$.

At present, there are a number of test-tube-based protein test kits dedicated to fast detection of substances on-site at bioterrorist events. One of the most popular is sold under the trade name BioCheck by 20/20 GeneSystems Inc. The BioCheck Powder Screening Test Kit is designed for first-responders to investigate suspicious powders for bioterrorism agents. The kit is characterised by remarkable ease of use. It consists of two tubes of reagents that identify the proteins and determine 
the $\mathrm{pH}$ of the test sample. According to the manufacturer's instructions (http:// biocheckinfo.com/schematic/), it takes up to 5 minutes to verify the presence of proteins. A positive test result is indicated by purple staining. The sensitivity of the BioCheck test is quite high, at about $10 \mu \mathrm{g} /$ test. The price of the kits is also not excessive, at EUR 1,000 for 25 kits (plus postage from the United States). The use of such a simple diagnostic test allows for the exclusion of the presence of biological hazards, or if confirmed, subsequent, more detailed testing can be carried out. This kit has mixture of protein detection reagent and strong lysing agent in tested tube which provide very variable results of analysis.

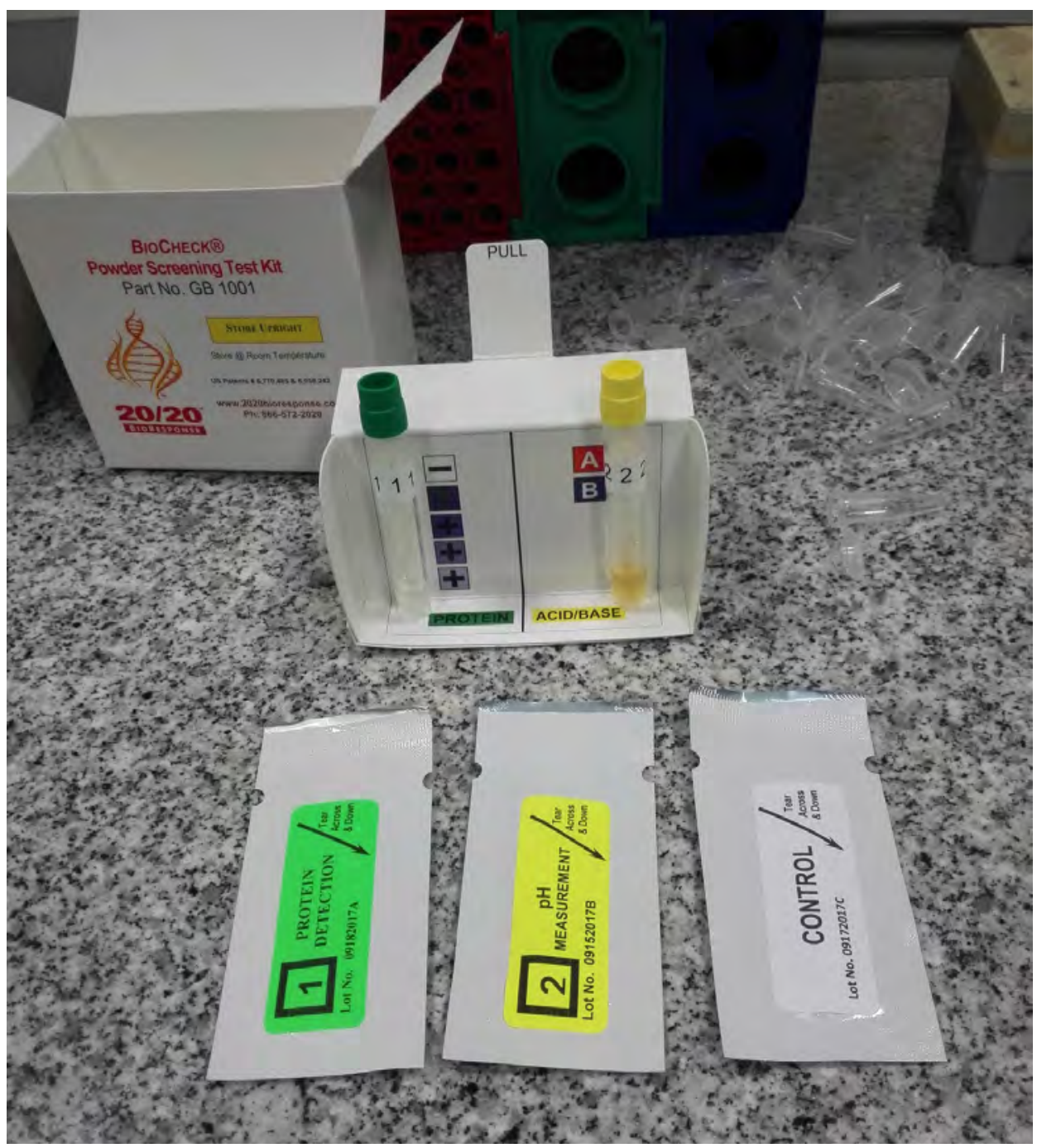

Figure 3. Composition of BIO-CHECK kit 


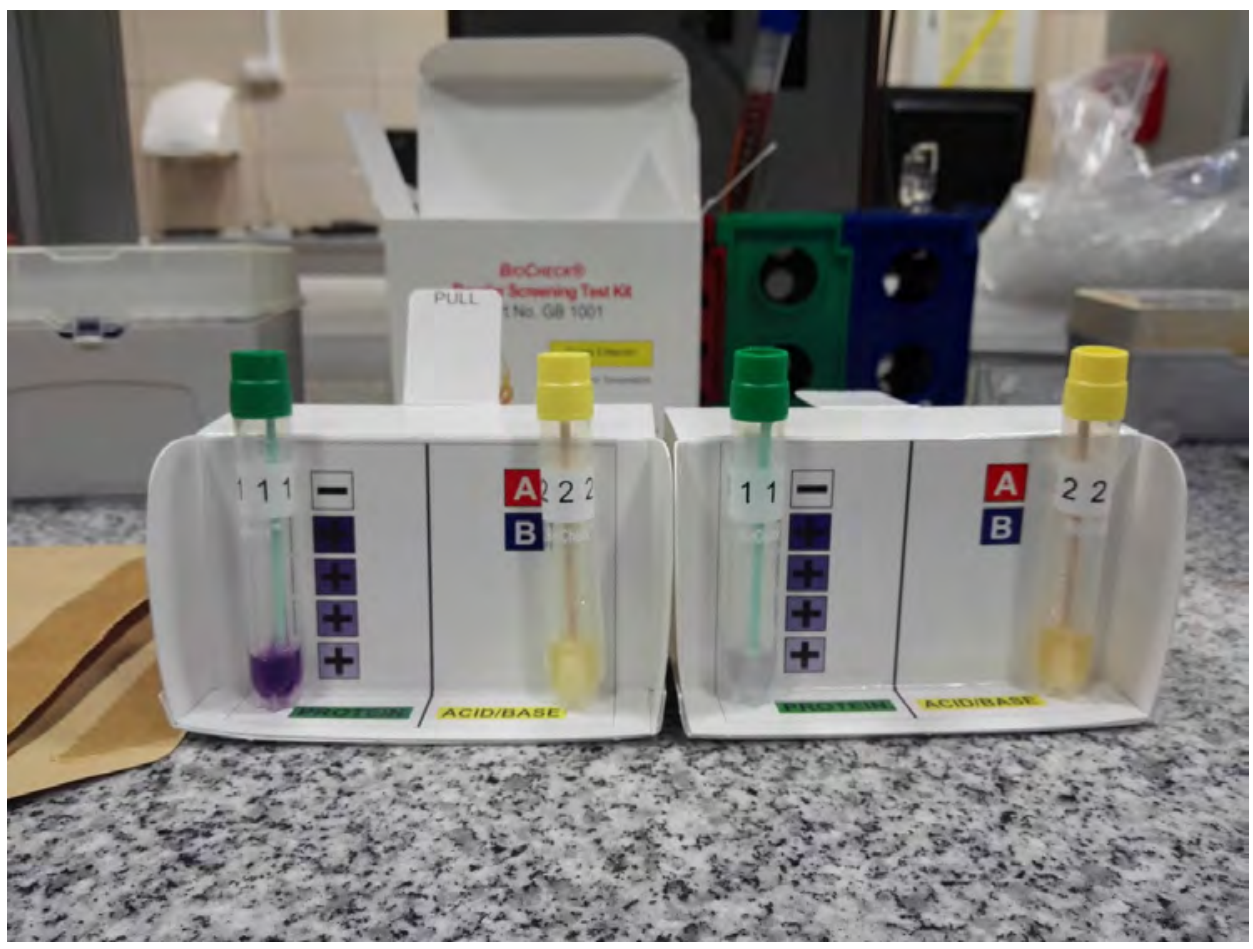

Figure 4. Positive and negative results of BIO-CHECK

\subsection{Immunoenzymatic tests}

The word 'immunoenzymatic' can be used to describe the types of analytical and diagnostic methods discussed in this text. They can be defined as the use of specifically designed antibodies (from immunoglobulins G, IgG) to enable detection of unique target proteins (antigens), after which the results are visualized via enzymatic reactions that can be classified as absorbance or fluorescence. Briefly, the biochemical background of immunoenzymatic reactions involves the use of antibodies dedicated to the protein of interest. The interaction of an antibody and its antigen is made possible due to the presence of specific epitopes (antigen determinants) in the target molecules or cells. Two types of antibodies are used in these assays: polyclonal and monoclonal antibodies. Polyclonal antibodies detect multiple epitopes in the antigen structure, while monoclonal antibodies are able to recognize only one epitope in the antigen.

In the case of proteins, antibodies are able to recognize the detected antigen on the basis of the amino acid sequence or three-dimensional structure of the polypeptide chain. The reaction is very selective and allows detection of even nanograms of the investigated protein (antigen). Antibody-antigen complexes are 
detected with the use of enzymatic reactions. The enzyme can be directly attached to the antibody structure, or added separately, in subsequent steps of the assay. The most frequently used enzymes are horseradish peroxidase (HRP) and alkaline phosphatase (AP). Substrates for these enzymes are commercially available as separate reagents, or are part of the assay kits. For the HRP enzyme, the most popular substrates are 3,3',5,5'-tetramethylbenzidine (TMB), (O-phenylenediamine dihydrochloride (OPD), and 2,2'-Azinobis [3-ethylbenzothiazoline-6-sulfonic acid]-diammonium salt (ABTS), while p-nitrophenyl phosphate (PNPP) is mainly used as a substrate for alkaline phosphatase.

Different types and variations of immunoenzymatic assays are widely applied in diagnostics, scientific research and the food industry. The most common variations include the Enzyme-Linked Immunosorbent Assay (ELISA), Western blotting, radioimmunoassays (RIA), lateral flow tests and protein microarrays.

\subsubsection{ELISA tests}

The Enzyme-Linked Immunosorbent Assay (ELISA) requires the use of a solid phase (usually a 96-well polystyrene microtiter plate). The plate is a base for antibody or antigen absorption (depending on the ELISA subtype used). In general, ELISAs may be classified into three main types: direct ELISAs, indirect ELISAs, and the 'sandwich' ELISA (an extended indirect ELISA). It should be emphasized, however, that ELISAs are often modified at different stages of their protocol, including in both the antigen immobilization stage and the detection/ probing steps. For example, antigens may be directly coated on microplate wells, or bound to antigen-specific antibodies that were previously adsorbed onto the microplate. In order to enhance the sensitivity of the tests, some modifications of the further stages can also be made. The secondary antibodies can be associated with biotin (vitamin $\mathrm{B}_{7}$ ). The biotin label enables further interactions with other components of the assay, including reactions with avidin (a protein of animal origin), and streptavidin (a protein isolated from Streptomyces avidinii bacteria), display a high ability to biotinylate itself or biotinylated molecules, and this connection is based on a strong, non-covalent reaction. This is very useful during construction of certain kinds of ELISA protocols. Enzymes used in immunoenzymatic assays can be conjugated with avidin or streptavidin. Biotinylated antibodies effectively bind the avidin- or streptavidin-labelled enzymes (HRP or AP). Although most of the available ELISA assays involve the use of enzymatic reactions to produce coloured products, ELISAs based on the fluorescent signal of antibodies labelled with fluorophores (immunoassays without enzymes) are also available. This type of immunoassay is particularly practical in conducting multiplex arrays that require simultaneous detection of more than one antigen (with the use of antibodies conjugated to different fluorophores). 
Direct ELISA. The antigen is detected in direct reaction with primary antibodies connected with the enzyme. Typically, the procedure contains four basal steps:

- Immobilization (coating) of antigens to the surface of microplate wells;

- Blocking of the remaining unsaturated surface-binding sites on the microplate wells by incubation with a solution of other proteins that are notreactive in this assay;

- Incubation with enzyme-coupled antibodies (probing);

- Detection - determination of enzyme activity products (visualisation of the results).

Indirect ELISA. The fundamental difference between direct and indirect ELISA is the use of secondary antibodies. The procedure for indirect assay involves the use of primary antibodies (recognising the antigen, but lacking the enzyme), and secondary antibodies (recognising the primary antibodies and bearing the enzyme). Thus, the procedure is longer when compared to the direct ELISA. However, the use of secondary antibodies significantly improves the sensitivity of the assay and decreases the extent of undesired non-specific effects. The simplest version of the indirect ELISA protocol can be presented in the following five steps:

- Immobilization (coating) of antigens to the surface of microplate wells;

- Blocking of the remaining unsaturated surface-binding sites on the microplate wells by incubation with a solution of other, not-reactive in this assay protein;

- Incubation with the primary antibodies (without the enzyme);

- Incubation with enzyme-coupled secondary antibodies (probing);

- Detection - determination of enzyme activity products (visualisation of the results).

Sandwich ELISA. This subtype of the ELISA was developed to potentiate the selectivity and sensitivity of immunodetection, especially when certain complex mixtures are assayed. The sandwich method is based on the use of two different antibodies that are able to bind specifically to the antigen, but recognizing different epitopes. The first antibodies (the 'capture' or 'coating' antibodies) are immobilized on the microplate well. The second antibodies are added to the antigen as a solution - this is the detection antibody.

A simple sandwich ELISA requires the following steps:

- Immobilization the first antibodies (capture/coating antibody) to the surface of microplate wells;

- Incubation with the antigen;

- Blocking of the remaining unsaturated surface-binding sites on the microplate wells by incubation with a solution of other, not-reactive in this assay protein;

- Incubation with the secondary antibodies (the detection antibody);

- Detection - determination of enzyme activity products (visualisation of the results). 
Furthermore, analogous to the indirect ELISA protocol, the sensitivity of the sandwich assay can also be enhanced with use of biotinylated secondary antibodies and avidin- or streptavidin-labelled enzymes.

\subsubsection{Western blot}

The western blot (also called western blotting or immunoblotting) is an analytical technique commonly used in biochemistry and molecular biology to identify particular proteins in a sample after its transfer to a membrane - the proteins are transferred by electric current into a thin membrane of nitrocellulose or Polyvinylidene Fluoride (PVDF), and are usually detected by specific antibodies.

To increase detection sensitivity, a sandwich of two layers of antibodies is usually used. The first antibodies are specific to the target protein, and the second antibodies are able to bind the first antibodies and start an enzymatic reaction, as they are conjugated with horseradish peroxide (HRP). The enzyme catalyses reactions in which colourful products, or chemiluminescence, appear. Images can be registered by cameras or scanners (the first case), or by digital dark chambers, sensitive sophisticated scanners and contact with light-sensitive photo paper (second case).

The membranes can be dyed with Amido Black or Ponceau $S$ dyes to visualize all transferred proteins. Only Ponceau S. staining is reversible, by rinsing with water, and can be used before immunodetection. The Amido Black dye is irreversible and disturbs the binding of antibodies, so it can be implemented only after immunodetection.

\subsubsection{Lateral Flow Assays}

Lateral flow assays (LFA) are the technology behind low-cost, simple, rapid and portable detection devices popular in biomedicine, agriculture, food and environmental sciences. Lateral flow immunoassays, also known as immunechromatographic assays, or strip tests, are unidirectional assays which are used to quickly and easily establish whether a target analyte is present in a test sample. Lateral flow immunoassays are essentially immunoassays adapted to operate along a single axis, to suit the test strip format. The lateral flow assay is a membrane-based platform for the detection and quantification of analytes in complex mixtures, in which the sample is placed on a test device. The results are displayed within 5-30 min.

The basic of this technology was first described in the 1960s, while the first real commercial application was Unipath's Clearview home pregnancy test, in 1988. Since then, the technology has been employed to develop a wide and evergrowing range of assays for clinical, veterinary, agricultural, food and bio-defence purposes. 
The advantages of the lateral flow immunoassay system are well-known, and include:

- High sensitivity and specificity;

- Only a low sample volume;

- Applicable in a wide range of settings;

- One-step assay, no wash steps necessary, short time to result;

- Possibility of multiplexing;

- Low cost;

- Simple, user-friendly operation;

- High potential for commercialization.

A typical lateral flow immunoassay consists of four key components: a sample application pad, a conjugate release pad, a nitrocellulose membrane and a wicking pad.

1. Sample pad - an adsorbent pad onto which the test sample is applied.

2. Conjugate or reagent pad - contains antibodies specific to the target analyte and conjugated to coloured particles (usually colloidal gold nanoparticles, or latex microspheres).

3. Reaction membrane - typically a nitrocellulose or cellulose acetate membrane onto which anti-target analyte antibodies are immobilized in a line that crosses the membrane to act as a capture zone or test line (a control zone will also be present, containing antibodies specific to the conjugate antibodies).

4. Wick or waste reservoir - a further absorbent pad designed to draw the sample across the reaction membrane by capillary action, and collect it.

The components of the strip are usually fixed to an inert backing material and may be presented as a simple dipstick, or within a plastic casing with a sample port and reaction window showing the capture and control zones.

The mechanism of analysis in lateral flow testing is very simple: a liquid sample (or its extract) containing the analyte of interest moves without the assistance of external forces (capillary action), through various zones of polymeric strips, on which molecules that can interact with the analyte are attached. The sample is applied at one end of the strip, on the adsorbent sample pad, which is impregnated with buffer salts and surfactants that make the sample suitable for interaction with the detection system. The sample pad ensures that the analyte present in the sample is capable of binding to the capture reagents of conjugates and on the membrane. Once soaked, the fluid migrates to the second element (conjugate pad), in which the manufacturer has stored the socalled conjugate, a dried format of bio-active particles in a salt-sugar matrix that contains everything to guarantee an optimized chemical reaction between the target molecule - an antigen and its chemical partner - antibody that has been immobilized on the particle's surface. The antibodies that are specific to the target analyte are conjugated to coloured or fluorescent particles, most commonly colloidal gold or latex microspheres. 
While the sample fluid dissolves the salt-sugar matrix, it also dissolves the particles, in one combined transport action. The sample, together with the conjugated antibody bound to the target analyte, migrates along the strip through the porous structure into the detection zone. This is a porous membrane with specific biological components immobilized in one or more lines (often called stripes). Their role is to react with the analyte bound to the antigen-conjugated antibody.

By the time the sample-conjugate mix reaches these strips, the analyte has been bound on the particle and the third 'capture' molecule binds the complex. Recognition of the sample analyte results in an appropriate response on the test line, while a response on the control line indicates the proper liquid flow through the strip. Typically, there are at least two stripes: one (the control) that captures any particle and thereby shows that the reaction conditions and technology worked properly; the second contains a specific capture molecule and only captures those particles onto which an analyte molecule has been immobilized. After passing these reaction zones the fluid enters the final porous material, the wick, which simply acts as a waste container. The read-out, represented by lines appearing with different intensities, can be assessed by eye or using a dedicated reader.

To test multiple analytes simultaneously under the same conditions, additional test lines of antibodies specific to different analytes can be immobilized in an array format.

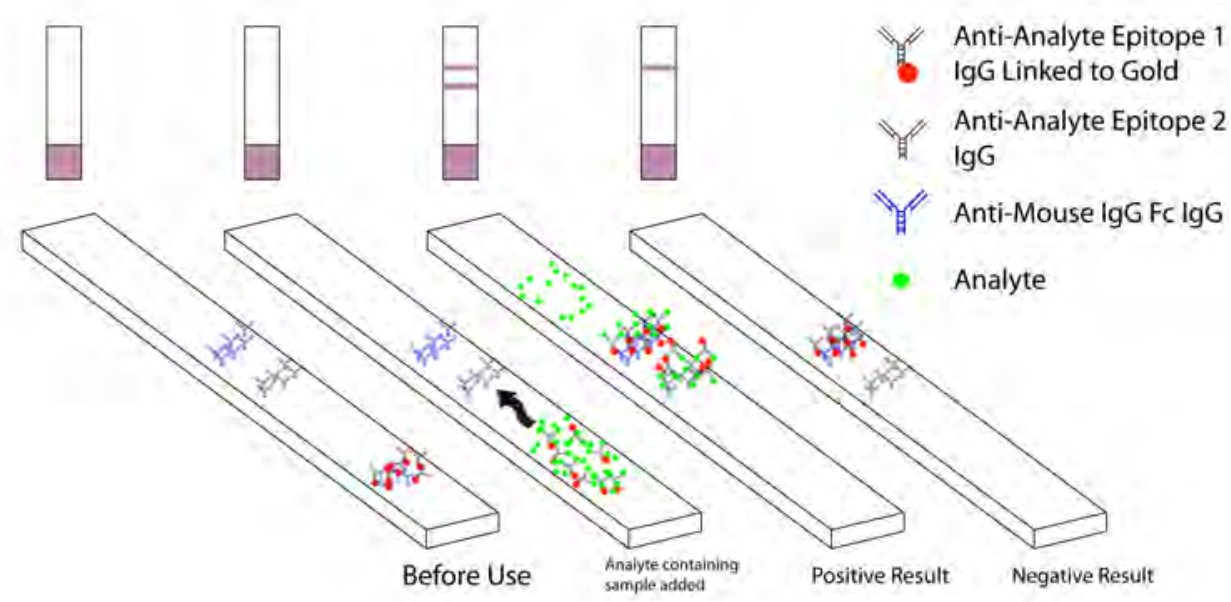

Figure 5. Scheme of lateral flow test analysis (figure used with permission under Creative Commons license)

Different commercially-available lateral flow tests dedicated to multiple bio-threat detection are available. The most popular are produced by Drager (BIO AGENT); Alexeter Technologies LLC (RAID (Rapid Assessment Initial 
Detection)), and BBI Detection (IMASS). BIO AGENT and RAID are typical lateral flow multiplex kits that contain a plate with equipment necessary for sampling, while the IMASS is quite different. IMASS stands for Integrated Multiplex Assay and Sampling System, and is an integrated system of sampling and fast detection in one kit. It provides the ability to rapidly sample powders, liquids or surfaces using an integrated sampling sponge. Once the sampling has been completed and the device is run, the sample is transferred simultaneously to all of the integrated assay strips.

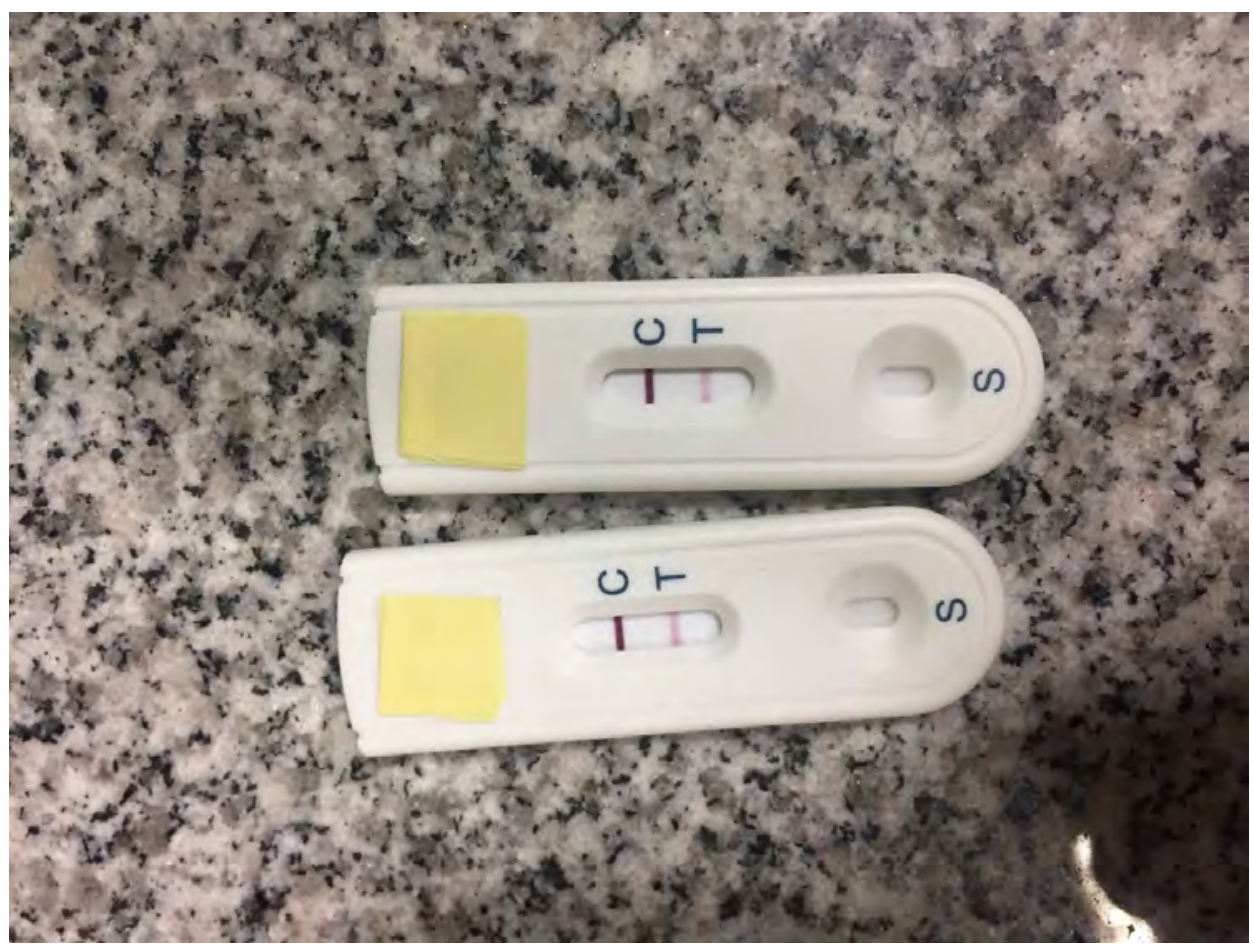

Figure 6. Positive results of lateral flow tests

\subsection{Flow cytometry}

Flow cytometry is a method that allows a sample of cells or particles in suspension to be separated through a narrow, rapidly flowing stream of liquid. Flow cytometry provides rapid analysis of multiple characteristics of single cells. In essence, a flow cytometer is a fluorescence microscope that collects light signals emitted from particles flowing across an objective lens. The information obtained is both qualitative and quantitative. The sample is passed through a laser, which allows for detection of size, granularity, and the fluorescent properties of 
individual cells/particles in the sample. Flow cytometry measurements are based on two types of markers: light scattering on the cell, and the fluorescence of labelled antibodies linked to antigens on the surface or inside the cell. This method consists in passing a liquid stream containing the test cells through a focused laser beam. In the flow cytometer, the cell suspension is pumped under vacuum in an envelope of screening liquid, in the form of a thin, flowing laminar stream containing a row of sequentially arranged cells (a so-called hydrodynamic focus). A fluorescently-labelled sample containing the particles of interest is connected to the flow cytometer, where the particles are oriented by hydrodynamic focusing into a thin stream surrounded by fluid of higher speed (sheet fluid). As a result of the interaction with the cell, the intensity of the scattered radiation is recorded by carefully selected and set up photomultiplier and photodetectors. For a few years, with the use of new generation fluorescent dyes, this method is significantly more sensitive, allowing for a much higher number of parameters and a lot of information from a single experiment. A beam of laser light is directed onto the stream of fluid and a number of detectors are aimed at the same point.

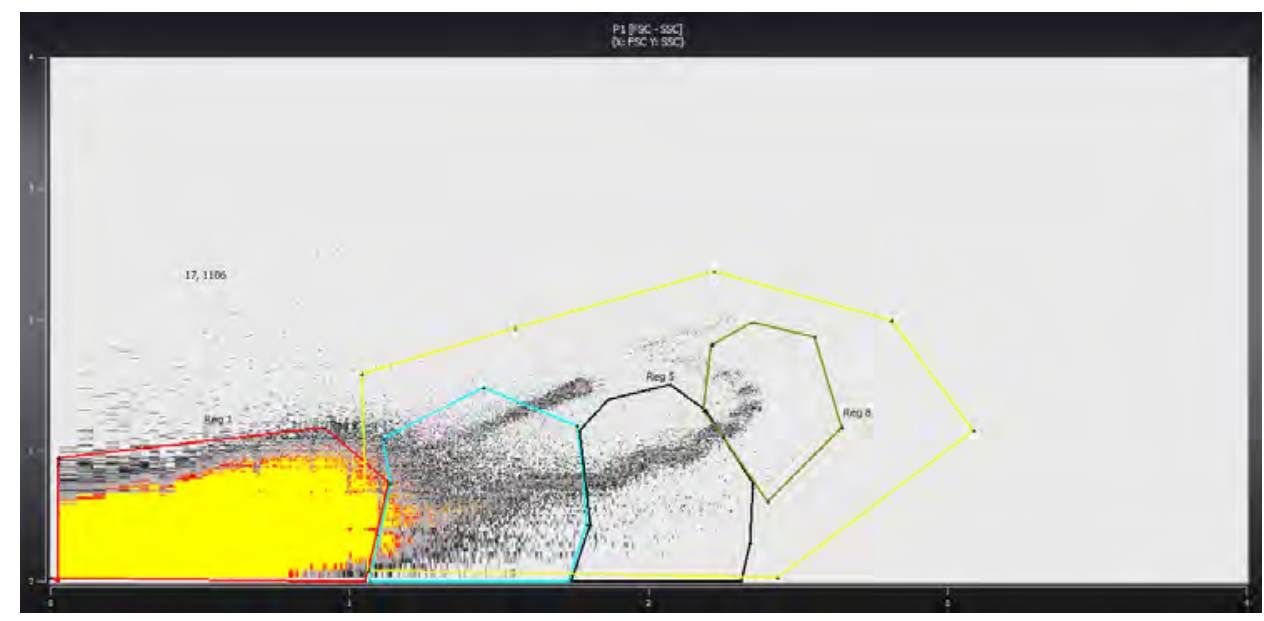

Figure 7. FSC vs SSC dot plot showing different cell populations

In light scattering analysis, two parameters are used. The first is Forward Scattering (FSC), for which the detector is mounted behind the measuring chamber. This first parameter carries information about cell size. It is assumed that the intensity of light is proportional to the size of the dispersion particle. The second parameter defines the light scatter perpendicular to the Side Scattering (SSC). The strength of this radiation is a defined function of the granularity of the illuminated cell - the more internal structures that diffuse the light beam, the greater the angle of diffused incident radiation. This in turn leads to an increase in 
the radiation intensity recorded at an angle of $90^{\circ}$. FSC and SSC detectors record signals for each specific object, so that the populations of the analysed cells can be distinguished or concluded on their own individual characteristics. Typically, particles in a range from 0.2 to 150 micrometres passing through the beam scatter the light at a detectable level based on SSC or FSC.

Flow cytometry measures the optical and fluorescence characteristics of single cells. Physical properties, such as size and internal complexity, can resolve certain cell populations. Fluorescent dyes may bind or intercalate with different cellular components, such as DNA and RNA. Additionally, antibodies conjugated to fluorescent dyes can bind specific proteins on cell membranes or inside cells. When labelled cells are passed by a light source, the fluorescent molecules are excited to a higher energy state. Upon returning to their resting states, the fluorochromes emit light energy at higher wavelengths. The use of multiple fluorochromes, each with similar excitation wavelengths and different emission wavelengths (or 'colours'), allows for several cell properties to be measured simultaneously.

Modern instruments usually have multiple lasers and fluorescence detectors allowing for a more complex experimental setup. The process of collecting data from samples using the flow cytometer is termed 'acquisition'. Acquisition is mediated by a computer connected to the flow cytometer and the software that handles the digital interface with the cytometer. Typically, a flow cytometer has five main components:

- A flow cell where the liquid stream (sheath fluid) that carries the cells/ particles is aligned, so that the cells/particles pass single-file through the light beam for sensing;

- A measuring system, commonly including diode lasers of different wavelengths (blue, green, red, violet), resulting in light signals;

- A detector, which is most often a Photo Multiplier Tube (PMT), and Analogue-to-Digital Conversion (ADC) system that turns FSC and SSC as well as fluorescence signals from light into electrical signals that can be processed by a computer;

- An amplification system (linear or logarithmic);

- A computer, for analysis of the signals.

Inside a flow cytometer, cells in suspension are drawn into a stream created by a surrounding sheath of isotonic fluid that creates a laminar flow, allowing the cells to pass individually through an interrogation point. At the interrogation point, a beam of monochromatic light, usually from a laser, intersects the cells. Emitted light is given off in all directions and is collected via optics that direct the light to a series of filters and dichroic mirrors that isolate particular wavelength bands. The light signals are detected by photomultiplier tubes and digitized for computer analysis. The resulting information is usually displayed in histogram or two dimensional dot-plot formats. In the case of histograms, the $\mathrm{x}$-axis will represent either fluorescence or scatter intensity collected from a single photo- 
detector on either a linear or logarithmic scale, and the y-axis represents the number of particles with the corresponding light intensity. For instance, if a cell is tagged with a fluorescently labelled antibody directed towards a surface protein, the fluorescence intensity will be directly proportional to the expression level of this antigen. By using multiple antibodies one can then assess the expression levels of several membrane-bound and/or intracellular proteins of a single cell. Any two of these parameters can be displayed simultaneously on two dimensional dot-plots.

Flow cytometry is a powerful technique for correlating multiple characteristics on single cells. This qualitative and quantitative technique has made the transition from a research tool to standard clinical testing.

Flow cytometry is routinely used in a number of research and diagnostic areas. In health care, flow cytometry is used to diagnose different diseases, including blood cancers, as well as for help with other clinical decisions in the fields of transplantation, haematology, tumour immunology and chemotherapy, genetics etc.

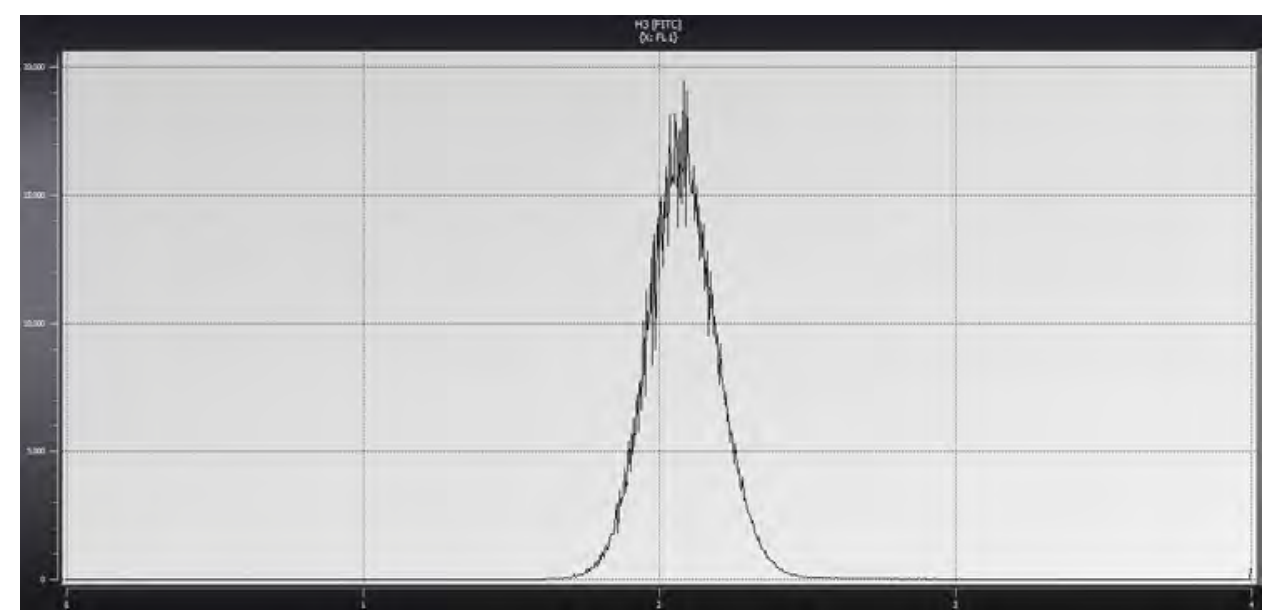

Figure 8. Fluorescence signal for cells connected with fluorescent antibodies

Using a combination of fluorescent dyes sensitive to cellular states, polyclonal antibodies targeting specific pathogens, specific assay additives, and a carefully defined cytometer gating logic, we can have a system for detecting target microbes in tested probes with a lot of advantages:

- Requires no or minimal enrichment;

- Achieves single cell sensitivity;

- Delivers a quantitative response;

- Offers analytical specificity (i.e. target pathogens without false negatives from non-target particles); 
- Provides consistent and robust instrumental operation;

- Utilizes reasonably stable and relatively inexpensive reagents;

- Does not require extensive operator training.

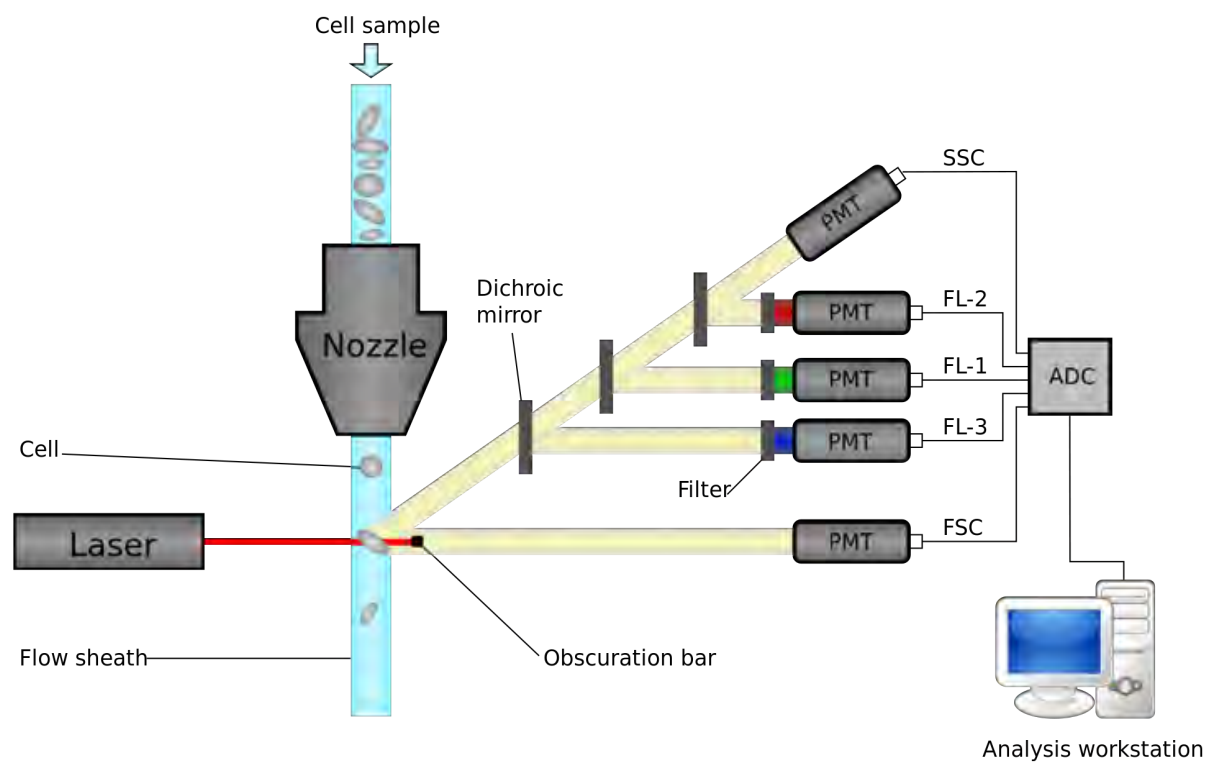

Figure 9. Scheme of flow cytometer mechanism (figure used with permission under Creative Commons license)

From the point of view of microbiologists, a key advantage of flow cytometry is the ability to simultaneously collect multiple data outputs from an individual cell. As bacteria are much smaller than mammalian cells, the detection and analysis of pathogenic microorganisms poses particular challenges for flow cytometry. For this reason very sensitive equipment is required. Additionally, beads are available for calibration and counting and are used as standards to provide a reference point allowing the operator to optimize instrument settings for detection of particular pathogens. These beads allow detection at a size level required for analysis of small particles, such as bacteria, and are available in a range of $0.1 \mu \mathrm{m}$ upwards. Fluorescence and sidescatter or forward scatter ratio information allow the operator to anticipate where, for example, labelled pathogens are located on a two-parameter plot. The concept of using flow cytometry to analyse bacterial presence in a sample is not new. However, the successful commercial development or modification of flow cytometers devoted entirely to the detection of a specific bacterial pathogen is still relatively uncommon.

As with most research and clinical equipment, flow cytometers are typically laboratory devices, but the development of the technique has led to their 
miniaturization, and nowadays, commercially-available mobile devices are available for field applications. One example of such a device used for field infection diagnosis in African countries is the $\mathrm{Cyflow}^{\circledR}$ miniPOC from Partec, which has a rechargeable battery dock (for 4-5 hours operation per battery charge). This equipment is dedicated to establishing populations of CD4/CD4\% cells, but other antibodies (for example, bacillus spores), can be used for pathogenic field detection.

\subsection{Real-time PCR}

Real-time polymerase chain reactions (real-time PCR), also known as real-time quantitative polymerase chain reactions (real-time-qPCR), allow for specific and highly sensitive quantification of nucleic acids. RT-PCR is based on a revolutionary method in molecular biology - PCR - which was developed by Kary Mullis in the 1980s. PCR allows for more than a billion-times amplification of specific fragments of DNA using sequence specific oligonucleotides, heat stable DNA polymerase, dNTPs and thermal cycling. A pair of primers are complementary to the sequence of interest, and during PCR reactions are extended by the DNA polymerase. The copies produced after the extension, so-called amplicons, are re-amplified with the same primers, thus leading to exponential amplification of the DNA molecules.

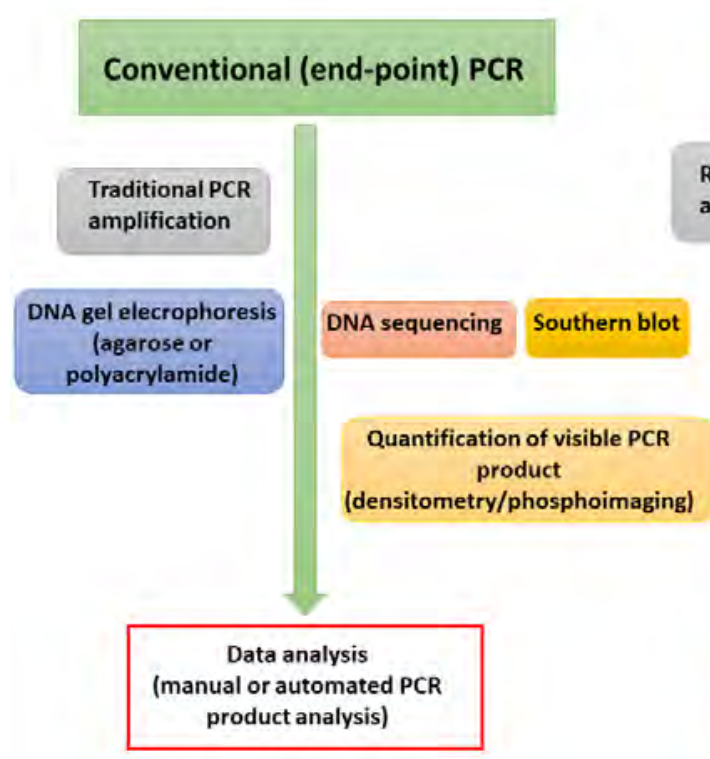

Data analysis (real-time PCR reaction quantitative results)

Figure 10. Conventional PCR versus Real-time PCR 
In conventional (traditional) PCR, detection and quantification of the amplified sequence (DNA product) are performed at the end of the reaction after the last PCR cycle - this is a so-called end-point analysis. After amplification, additional postPCR analysis, such as gel electrophoresis (agarose or polyacrylamide) and image analysis are required, and this makes conventional PCR time consuming. Realtime-qPCR overcomes this problem - the amplified DNA product is measured in each cycle, as the reaction progresses.

The advantages of real-time PCR include:

- Ability to precisely measure the amount of amplicon in each cycle, which allows for highly accurate quantification of the amount of DNA starting material in each sample;

- Ability to monitor the PCR reaction progress in real time;

- Amplification and detection of PCR product occurs in a single tube, eliminating post-PCR manipulations (high throughput, low contamination risk);

- Elimination of non-specific amplification;

- Confirmation of specific amplification by melting curve analysis;

- Most specific, sensitive and reproducible;

- Not much more expensive than conventional PCR (except for the cost of the Thermal Cycler);

- Increased dynamic detection range (up to $10^{10}$ ).

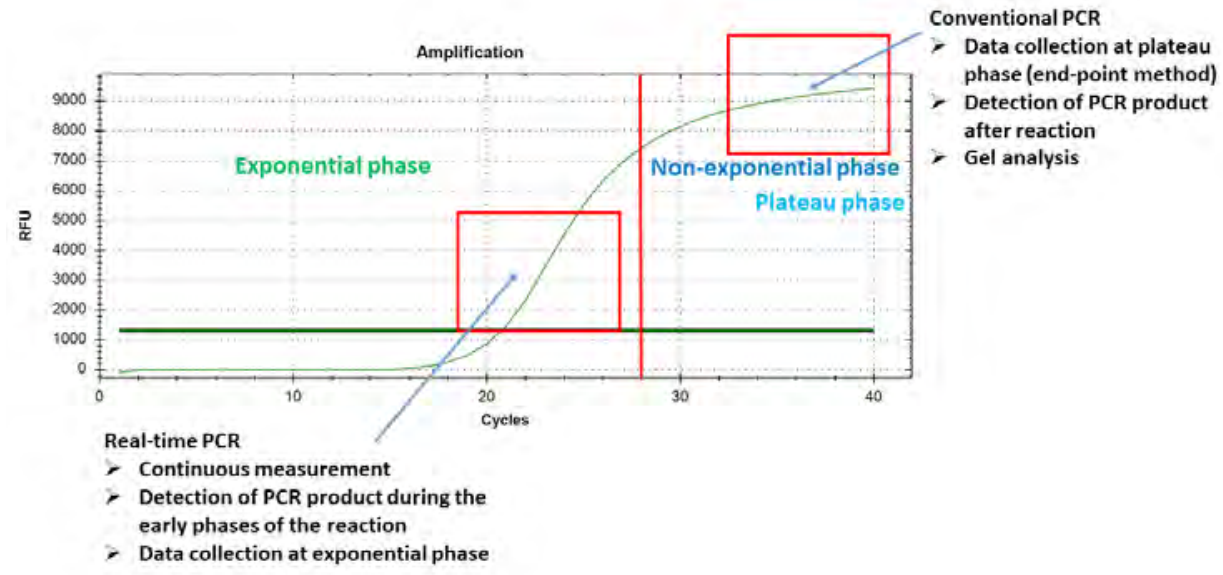

Figure 11. Reaction kinetics in real-time PCR. Comparison conventional PCR with real-time PCR

To better understand the differences between conventional PCR and Realtime PCR and how real-time PCR works, in Figure 2 we show the kinetics of the PCR reaction using a typical amplification plot. On the $\mathrm{x}$-axis the number of PCR cycles is shown, while on the $y$-axis is the fluorescence from the PCR 
amplification reaction, proportional to the amount of amplified product in each tube. Generally, an amplification curve presents three different phases:

1. Exponential;

2. Non-exponential;

3. Plateau or end-point phase.

During the exponential phase, all components are present in a sufficiently high quantity to guarantee good amplification, and the amount of PCR product approximately doubles in each cycle. As the cycles progress and reagent components of the reaction begin to be depleted, the reaction will begin to slow down, the PCR product will no longer be doubled in every cycle, and nonexponential amplification will occur where the samples begin to diverge in their quantities. After several rounds of PCR amplification, the PCR reaction will no longer generate a template, due to the lack of critical reagents in the reaction tube. This is commonly referred to as the plateau phase, or end-point.

All samples that start with the same quantity of all PCR components and DNA concentration at the beginning of the reaction will end up at different points in the plateau phase, due to the different kinetics each sample had during thermal cycling. More precise measurements are made during the exponential phase, in which the replicate samples are amplified exponentially. Therefore, only in the exponential phase in a real-time reaction is quantification possible. In conventional PCR, the amplified products are analysed by gel electrophoresis (size-fractionation), and visualized by ethidium bromide. This process will therefore measure the final DNA obtained during the PCR reaction, which can be compared to measuring the amount of DNA in the plateau phase. At this point, quantification is exceedingly difficult, since the PCR gives essentially the same amount of PCR product independently of the initial amount of DNA template molecules that were present at the beginning.

\subsubsection{Basic terms used in real-time PCR}

Before the levels of a nucleic acid (DNA or cDNA) target can be quantified and analysed by real-time PCR assay, the raw data must be processed. Basic terms used in data analysis are described below, and in Figure 12.

\section{Baseline}

The baseline of the real-time PCR reaction is the signal level during the initial cycles of PCR, usually cycles 3 to 18, in which increases in fluorescence are not detectable. The baseline in real-time PCR can be determined empirically by user analysis for each reaction, or automated analysis of the real-time amplification plot. The baseline should be carefully set to allow accurate determination of the threshold cycle ( $\mathrm{Ct}$; defined below). The baseline determination should take into 
account enough cycles to eliminate the background found in the early cycles of amplification, but should not include the cycles in which the amplification signal begins to rise above the background.

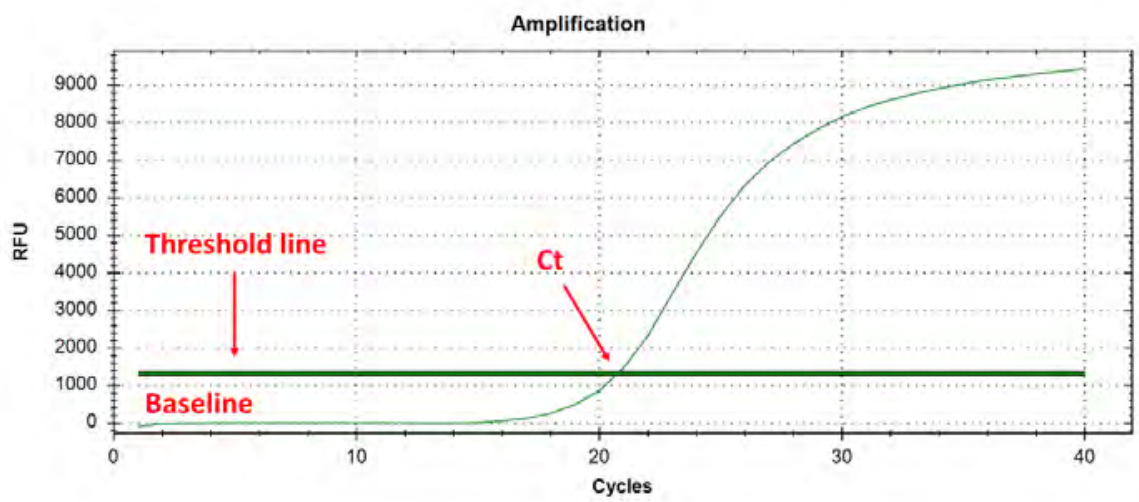

Figure 12. Example of a single amplification plot illustrating the nomenclature commonly used in real-time PCR

\section{Threshold}

The threshold of the real-time PCR reaction is the level at which the signal shows a statistically significant increase over the calculated baseline signal. Threshold is set to distinguish relevant amplification signal from background, and must be set within the linear region of the amplification curve, which represents the detectable log-linear range of the PCR. Generally, real-time PCR instrument software automatically sets the threshold at 10 times the standard deviation of the fluorescence value of the baseline.

\section{Ct (threshold cycle)}

The threshold cycle $(\mathrm{Ct})$ is the cycle number at which the fluorescent signal of the reaction crosses the threshold. The Ct allows calculation of the starting template amount present in the reaction, because the $\mathrm{Ct}$ value is measured in the exponential phase when the reagents are not limited. The Ct of a real-time PCR reaction is determined mainly by the amount of template $\mathrm{DNA} / \mathrm{cDNA}$ present at the start of the amplification reaction. If a large amount of template is present at the start of the reaction, relatively few amplification cycles will be required to accumulate enough product to give a fluorescence signal above background. Thus, the reaction will have a low Ct. In contrast, if a small amount of template 
is present at the start of the reaction, more amplification cycles will be required for the fluorescence signal to increase above background. Thus, the reaction will have a high Ct. This relationship forms the basis for the quantitative aspect of real-time PCR.

\section{$\Delta C T$ value}

The $\Delta \mathrm{CT}$ value describes the difference between the $\mathrm{CT}$ value of the target gene and the CT value of the corresponding endogenous reference gene (socalled housekeeping gene) and is used to normalize for the amount of template by following formula:

$$
\Delta \mathrm{CT}=\mathrm{CT}(\text { target gene })-\mathrm{CT}(\text { endogenous reference gene })
$$

\section{Efficiency and slope}

The slope of the log-linear phase of the amplification reaction provides an indication of the efficiency of the real-time PCR. To obtain accurate and reproducible results, reactions should have an efficiency as close to $100 \%$ as possible, equivalent to a slope of -3 . 32. The efficiency of a real-time PCR assay can be calculated by analysing a template dilution series, plotting the CT values against the log template amount, and determining the slope of the resulting standard curve. From the slope (S), efficiency can be calculated using the following formula:

$$
\text { PCR efficiency }(\%)=(10(-1 / S)-1) \times 100
$$

Generally, most amplification reactions do not reach $100 \%$ efficiency due to experimental limitations.

\subsubsection{Real-time PCR reaction components}

As in traditional PCR, real-time PCR reaction requires the addition of deoxynucleotides (dNTPs) solution mix, reaction buffer, sequence-specific primers, Taq polymerase, magnesium and water. Moreover, real-time PCR requires one additional component, either a fluorescent dye that binds double stranded DNA or a fluorescent labelled probe.

\section{Thermostable DNA polymerase}

DNA polymerases play the most important role in replicating the targetDNA/ cDNA. Taq DNA polymerase, isolated from the eubacterium Thermusaquaticus, is the most commonly-used enzyme for standard end-point PCR, as well as real- 
time PCR reactions. Taq DNA polymerase has relatively high thermostability, with a half-life of approximately 40 minutes at $95^{\circ} \mathrm{C}$. It incorporates nucleotides at a rate of about 60 bases per second at $70^{\circ} \mathrm{C}$ and can amplify lengths of about $5 \mathrm{~kb}$. One of the key factors which affecting PCR specificity is the fact that Taq DNA polymerase has residual activity at low temperatures. Primers can anneal nonspecifically to DNA, allowing the polymerase to synthesize nonspecific product. This problem can be minimized by using a 'hot-start' enzyme. Using a hot-start enzyme ensures that no DNA polymerase is active during the reaction setup or the initial DNA denaturation step. Usually, the optimal concentration of Taq DNA Polymerase ranges from 5-50 units/ml (0.25-2.5 units/50 $\mu$ l reaction), are sufficient for amplification of target DNA/cDNA.

\section{Deoxynucleotides (dNTPs) solution mix}

A dNTPs solution mix is used in real-time PCR reactions, is an equimolar solution of ultrapure dATP, dCTP, dGTP and dTTP, and is used as the building blocks of new DNA/cDNA strands. These four nucleotides are typically added to the PCR reaction in equimolar amounts for optimal base incorporation. In common real-time PCR applications, the recommended final concentration of each dNTP is generally $0.2 \mathrm{mM}$. Note, however, that dNTPs exceeding optimal concentrations can inhibit real-time PCR reaction.

\section{Template}

Both traditional PCR as well as real-time PCR templates for replication can have any DNA source, such as genomic DNA (gDNA), complementary DNA (cDNA), or plasmid DNA. Recommended amounts of DNA template for a $50 \mu \mathrm{l}$ reaction are as follows: 10 to 1,000 copies of template nucleic acid for each realtime PCR reaction. This is equivalent to approximately $100 \mathrm{pg}$ to $1 \mu \mathrm{g}$ of genomic DNA, or cDNA generated from $1 \mathrm{pg}$ to $100 \mathrm{ng}$ of total RNA. Note, however, that excess template nucleic acid can bring with it higher contaminant levels that can greatly reduce PCR efficiency. Depending on the specificity of the PCR primers for cDNA rather than genomic DNA, it may be important to treat RNA templates to reduce the chance that they contain genomic DNA contamination. One of the better options is to treat the template with DNase I.

\section{Primers (sequence-specific oligonucleotides)}

Oligonucleotides, also known as 'oligos' or 'primers', are short (approx. 15-30 bases), single-stranded polymers of nucleic acid. PCR primers are designed to bind by sequence complementarity to sequences that flank the region of interest in the template DNA/cDNA. During PCR amplification, 
DNA polymerase extends the primers from their 3' ends. As such, the primers' binding sites must be unique to the vicinity of the target with minimal homology to other sequences of the input DNA to ensure specific amplification of the intended target. Generally, primers should be 18-24 nucleotides in length. This provides for practical annealing temperatures. In addition, primers should be designed according to standard PCR guidelines. They should be specific to the target sequence and be free of any internal secondary structure. Primers should avoid stretches of homopolymer sequences (e.g. poly (dG)) or repeating motifs, as these can hybridize inappropriately. Primer pairs should have compatible melting temperatures (within $5^{\circ} \mathrm{C}$ ) and contain approximately $50 \% \mathrm{GC}$ content. Primers with high GC content can form stable imperfect hybrids. Conversely, high AT content depresses the Tm of perfectly matched hybrids. If possible, the 3 ' end of the primer should be GC-rich (GC clamp) to enhance annealing of the end that will be extended. Primer pair sequences should be analysed to avoid complementarity and hybridization between primers (primer-dimers).

Primers for qRT-PCR reactions should ideally be designed to span an exonexon junction, with one of the amplification primers potentially spanning the actual exon-intron boundary of the mRNA, to allow differentiation between amplification of cDNA and potential contaminating genomic DNA by melting curve analysis. To confirm the specificity of designed primers, a BLAST search of public databases should be performed, to ensure that primers only recognize the target of interest. It has been shown that the amplicon length should be approximately $50-150 \mathrm{bp}$, as longer products do not amplify as efficiently and because the final concentration of $200 \mathrm{nM}$ for each primer is effective for most reactions.

Optimal primer sequences and appropriate primer concentrations are essential for maximal specificity and efficiency in both traditional PCR and realtime PCR. Good primer design is one of the most important parameters in realtime PCR, and is especially critical when using DNA-binding dyes for amplicon detection. There are multiple free primer design tools available online that produce high quality primers based on the criteria listed above. One popular web-based program for primer design is Primer3.0 (http://bioinfo. ut. ee/primer3-0.4.0/.)

\section{Magnesium}

Magnesiumion $\left(\mathrm{Mg}^{2+}\right)$ functions as a cofactorforactivity ofDNA polymerases by enabling incorporation of $\mathrm{dNTPs}$ during DNA/cDNA polymerization. The magnesium ions at the enzyme's active site catalyse phosphodiester bond formation between the $3^{\prime}-\mathrm{OH}$ of a primer and the phosphate group of a dNTP. Furthermore, $\mathrm{Mg}^{2+}$ facilitates formation of the complex between the primers and DNA templates by stabilizing negative charges on their phosphate backbones. In real-time PCR, magnesium chloride or magnesium sulfate is typically used at a final concentration of $3 \mathrm{mM}$. It has been shown that this concentration works 
very well for most targets, however the optimal magnesium concentration can vary between 3 and $6 \mathrm{mM}$. Note, however, that low $\mathrm{Mg}^{2+}$ concentrations result in little or no PCR product, because of the polymerase's reduced activity. On the other hand, high $\mathrm{Mg}^{2+}$ concentrations often produce nonspecific PCR products from enhanced stability of primer-template complexes, as well as increases in replication errors from mis-incorporation of dNTPs.

\subsubsection{Real-time PCR protocol}

There are three main steps that make up each cycle in a real-time PCR reaction: denaturation, annealing and extension, which are described in detail below.

1. Denaturation step: High temperature incubation is used to 'melt' doublestranded DNA into single strands and loosen the secondary structure in singlestranded DNA. The highest temperature that the DNA polymerase can withstand is typically used (usually $95^{\circ} \mathrm{C}$ ). The denaturation time can be increased if the GC template content is high.

2. Annealing step: During this phase, complementary sequences have an opportunity to hybridize, so an appropriate temperature is used, based on the calculated melting temperature $(\mathrm{Tm})$ of the primers $\left(5^{\circ} \mathrm{C}\right.$ below the $\mathrm{Tm}$ of the primer).

3. Extension step: At $70-72^{\circ} \mathrm{C}$, the activity of the DNA polymerase is optimal, and primer extension occurs at rates of up to 100 bases per second. When an amplicon in real-time PCR is small, this step is often combined with the annealing step using $60^{\circ} \mathrm{C}$ as the temperature.

\subsubsection{Reverse Transcription Quantitative PCR (RT-qPCR) - RNA as the starting material}

RT-qPCR terms is used when RNA is a starting material. It is used in a variety of applications, such as gene expression analysis, RNA validation, microarray assays, pathogen detection and also various genetic tests. In general, two methods are available for quantification of gene expression by RT-qPCR: two-step RT-qPCR and one-step RT-qPCR. In both cases, RNA is reversetranscribed into cDNA, and the cDNA is then used as the template for qPCR amplification. 'One-step' and 'two-step' refer to whether the RT and real-time PCR amplification are performed in the same, or separate tubes. In the twostep method, RNA is first transcribed into $\mathrm{cDNA}$ in a reaction using reverse transcriptase. Reverse transcriptase is an enzyme that makes a molecule of DNA from an RNA template. Some enzymes have RNase activity that allows for degradation of the RNA strand in the RNA-DNA hybrid after transcription. If an enzyme does not possess RNase activity, an $\mathrm{RNaseH}$ may be added for 
better qPCR efficiency. Commonly used enzymes include Moloney murine leukaemia virus reverse transcriptase, and Avian myeloblastosis virus reverse transcriptase. RNA is reverse transcribed into cDNA using oligo-dT primers, random oligomers, or gene-specific primers. Next, an aliquot of the resulting cDNA is then used as a template for multiple qPCR reactions. In the one-step method, RT and qPCR are performed in the same tube, and so this method is also referred to as 'one-tube RT-PCR'.

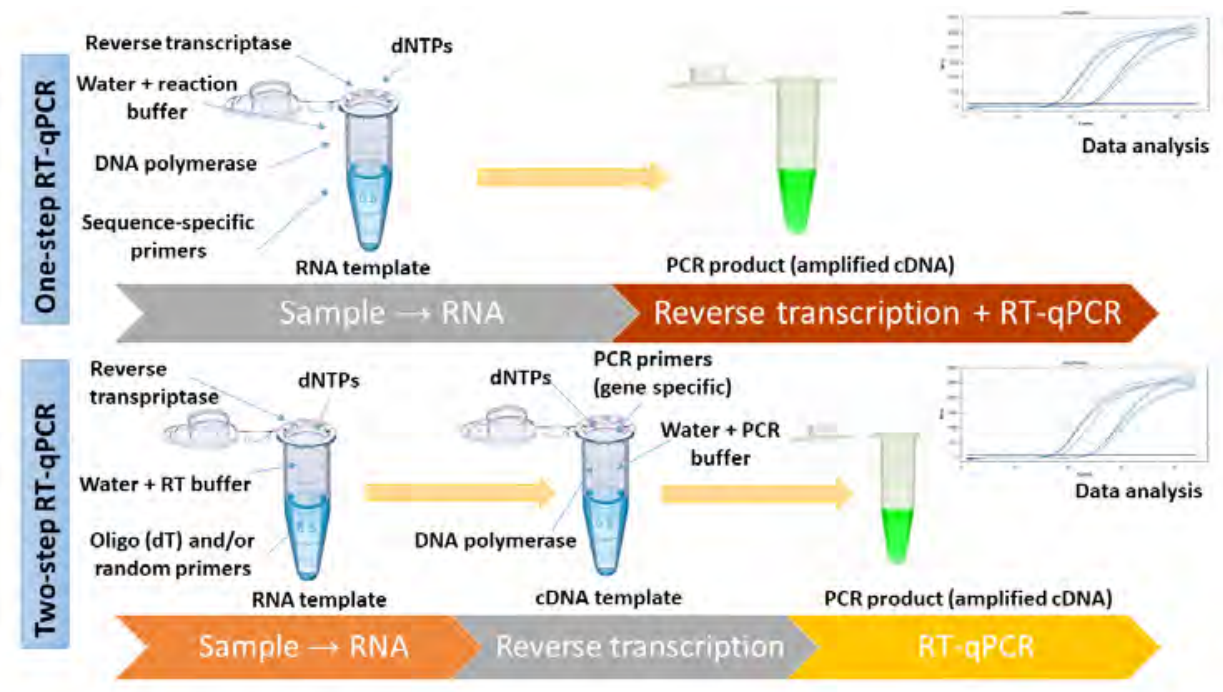

Figure 13. One-step vs two-step RT-PCR (figure used with permission under Creative Commons license)

\subsubsection{PCR product detection in real-time $P C R$}

Real-time PCR and RT-PCR allow for accurate quantification of starting amounts of DNA, cDNA, and RNA targets. Fluorescence is measured during each cycle, which greatly increases the dynamic range of the reaction, since the amount of fluorescence is proportional to the amount of PCR product. PCR products can be detected using either fluorescent dyes that bind to double-stranded DNA (e.g. SYBR ${ }^{\otimes}$ Green I and EvaGreen), or fluorescently labelled sequence-specific probes, such as TaqMan and Molecular beacons. The change in fluorescence over the course of the reaction is measured by an instrument that combines thermal cycling with fluorescent dye scanning capability. By plotting fluorescence against the cycle number, the real-time PCR instrument generates an amplification plot that represents the accumulation of product over the duration of the entire PCR reaction. 


\subsubsection{Molecular detection of Bacteria by real-time qPCR assays}

\section{Bacterial genome}

Deoxyribonucleic acid (DNA) is present in all living organisms. This amazing macromolecule encodes all of the information needed to program a cell's functions, such as reproduction, metabolism and other specialized functions. DNA is comprised of two strands of deoxynucleotides. Each deoxynucleotide contains a phosphate, a 5-carbon sugar (2-deoxyribose), and one of four nitrogenous bases: adenine, cytosine, thymine or guanine. The phosphate and sugar make up the backbone of each strand of DNA, while the bases are responsible for holding the two strands together via hydrogen bonds in a structure called the double helix. The order of the bases in a DNA strand contains the coded genetic information. All of the DNA found in an organism is collectively referred to as the genome.

Bacterial genomes are generally smaller and less variant in size among species when compared with genomes of animals or single cell eukaryotes. Generally, a bacterial genome is composed of a single, circular chromosome. In addition, bacteria may have one or more smaller circular DNA molecules, called plasmids, that contain (usually) non-essential genes.

Bacterial identification methods based on biochemical tests, such as API system and conventional culture methods, have been traditionally used for the detection and identification of pathogens. In recent years, new molecular methods based on DNA amplification and quantitative polymerase chain reaction (qPCR) have been proposed for the rapid and high-sensitive detection of pathogens.

\section{DNA and RNA extraction from bacteria}

To extract a functional macromolecular component from bacterial cells, three things need to happen:

1. Efficient disruption of the bacterial cell wall and cell-membrane system, to facilitate extraction of the desired components.

2. Everything must be done under conditions that either inhibit or destroy the many degradative enzymes released during cell disruption, including the nucleases and proteases.

3. You must employ a fractionation procedure that separates the desired macromolecule from other cellular components with high-efficiency and purity.

The typical procedure for genomic DNA preparation from a culture of bacterial cells can then be divided into four steps:

1. Probing the sample.

2. Preparation of a cell extract (lysozyme, EDTA or combination of both; SDS). 
3. Purification of DNA from a cell extract (organic extraction; phenol or phenol chloroform, or enzyme digestion - protease, ribonuclease).

4. Concentration of DNA samples (ethanol precipitation).

RNA isolation from a bacterial cells is based on the following principle: RNA is separated from DNA after extraction with an acidic solution containing guanidinium thiocyanate, sodium acetate, phenol and chloroform, followed by centrifugation. Under acidic conditions, total RNA remains in the upper aqueous phase, while most of the DNA and proteins remain either in the interphase or the lower organic phase. Next, total RNA is then recovered by precipitation with isopropanol.

Either total RNA can be used for most real-time RT-qPCR applications. One critical consideration in working with RNA is to eliminate RNases in your solutions, consumables and labware. RNase-free solutions can be purchased, or your solutions can be treated with diethyl pyrocarbonate (DEPC), and then autoclaved. RNases on labware can also be inactivated with DEPC treatment or by baking at $250^{\circ} \mathrm{C}$ for $3 \mathrm{~h}$. Extracted RNA samples may also need DNase treatment to prevent potential amplification of any contaminating genomic DNA, which could lead to overestimation of the copy number of an mRNA.

\subsubsection{Detection and quantification of Bacillus sp. by real-time qPCR methods}

A large number of real-time PCR procedures are available for the specific detection and quantification of these bacteria, which are described below.

\section{SYBR Green-based real-time qPCR assays}

SYBR Green assay uses a pair of PCR primers that amplifies a specific region within the target sequence of interest and includes a double-stranded DNA (dsDNA)-binding dye for detecting the amplified product. A SYBR Green qPCR reaction contains the following components:

- PCR master mix with SYBR Green dye;

- DNA template;

- Specific primers.

It can be used for the following assay types:

- One-step RT-PCR for RNA quantitation;

- Two-step RT-PCR for RNA quantitation;

- DNA/cDNA quantitation.

SYBR Green binds to the minor groove of dsDNA - when it is free in a solution it displays relatively low fluorescence levels, but when dsDNA is added, the fluorescence increases over 1,000 times. Therefore, the greater the amount of dsDNA present in the reaction tube, the greater the amount of DNA 
binding and fluorescent signal from the SYBR Green. As the accumulation of new amplicons increases with the PCR reaction cycles, the intensity of fluorescence also increases, because more SYBR Green molecules bind to the dsDNA. Thus, the accumulation of product can be measured in real time. However, nonspecific PCR products and primer-dimers also contribute to the fluorescent signal. Therefore, qPCR reactions using SYBR Green should be sensitive and specific, and should exhibit good amplification efficiency over a broad dynamic range. In addition, melt-curve analysis of reaction product from a SYBR Green assay should be used to distinguish specific products from non-specific products.

\section{TaqMan probe-based real-time PCR assays}

A TaqMan probe assay uses a pair of PCR primers and a dual-labelled, targetspecific fluorescent probe. A TaqMan probe-based qPCR reaction contains the following components:

- PCR master mix;

- DNA/cDNA template;

- Primers;

- Probe(s).

TaqMan probes are also known as 5'-nuclease probes, because the 5'-exonuclease activity of DNA polymerase cleaves the probe. In terms of structure, hydrolysis probes are sequence- specific dually fluorophore-labelled DNA oligonucleotides. One fluorophore is the 'quencher', and the other is the 'reporter.' When the quencher and the reporter are in close proximity - that is, they are both attached to the same short oligonucleotide - the quencher absorbs the signal from the reporter. This is an example of fluorescence resonance energy transfer (also referred to as a 'Forster transfer'), in which energy is transferred from a 'donor' (the reporter) to an 'acceptor' (the quencher) fluorophore. During DNA amplification, the oligonucleotide is broken apart by the action of DNA polymerase (5'-nuclease activity), and the reporter and quencher separate, allowing the reporter's energy and fluorescent signal to be liberated. Thus, destruction or hydrolysis of the oligonucleotide results in an increased reporter signal, and corresponds with the specific amplification of DNA. As with SYBR Green assays, an optimized TaqMan assay should be sensitive and specific, and should exhibit good amplification efficiency over a broad dynamic range.

The TaqMan probe can be used for the following assays:

- One-step RT-PCR for RNA quantitation;

- Two-step RT-PCR for RNA quantitation;

- DNA/cDNA quantitation.

Over numerous studies, this method has been developed and validated for quantitative and specific detection of Bacillus spp. 


\section{References}

Eischeid A.C., SYTO dyes and EvaGreen outperform SYBR Green in real-time PCR, BMC Res Notes 2011, no. 4.

Grasza M., Szemraj J., Bijak M., Detekcja czynnika w ramach działań kontrterrorystycznych w przypadku zagrożenia bioterrorystycznego, Policja Kwartalnik Kadry Kierowniczej Policji 2015, no. 16.

Koczula K.M., Gallotta A., Lateral flow assays, Essays Biochem 2016, no. 60.

Kłyszejko-Stefanowicz L., Ćwiczenia z biochemii, Wyd. Nauk. PWN 2005.

Lodish H., Berk A., Zipursky L., Matsudaira P., Baltimore D., Darnell J., Molecular Cell Biology, New York: W H Freeman 2000.

Mackay I.M., Real-time PCR in the microbiology laboratory, Clin Microbiol Infect 2004, no. 10.

Mackay I.M., Arden K.E., Nitsche A., Real-time PCR in virology, Nucleic Acids Res 2002, no. 30 .

Noble J., Bailey M., Quantitation of Protein, Methods in Enzymology 2009, no. 463.

Okutucu B., Dincer A., Habib O., Zihnioglu F., Comparison of five methods for determination of total plasma protein concentration, J Biochem Biophys Methods 2007, no. 70.

Sajid M., Kawde A., Daud M., Designs, formats and applications of lateral flow assay: A literature review, Journal of Saudi Chemical Society 2015, no. 19.

Sędek Ł., Sonsala A., Szczepański T., Mazur B., Technical aspects of flow cytometry, Journal of Laboratory Diagnostic 2010, no. 46.

Shapiro H., Practical flow cytometry, John Wiley \& Sons 2003.

Skotny A., Pucińska J., Modern flow cytometry, Acta Bio-Optica et Informatica Medica 2013, no. 19.

Studzińska A., Tyburska J., Daca P., Tretyn A., PCR w czasie rzeczywistym. Istota metody i strategie monitorowania przebiegu reakcji, Biotechnologia 2008, no. 80.

ThermoScientific. Thermo Scientific Pierce Protein Assay Technical Handbook 2010.

Vrsanska M., Kumbar V., A comparison of biuret, lowry and bradford methods for measuring the egg's proteins. Mendel Net. 2015.

Wyczałkowska-Tomasik A., Żegarska J., Łańcuchowa reakcja polimerazy w czasie rzeczywistym. Zastosowanie $w$ badaniach naukowych $i$ diagnostyce medycznej, Przegląd Lekarski 2009, no. 66. 